\title{
The Drive to Succeed: The Instructional Leader
}

\author{
Derrick Love* \\ Administrator, Chief Executive Officer, USA
}

Received: 阱: November 13, 2018; Published: 制: November 26, 2018

*Corresponding author: Derrick Love, Administrator, Chief Executive Officer, Arizona, USA

\section{Opinion}

Instructional leaders spend countless hours contemplating how to increase teacher efficacy that will influence directly to student achievement in the classroom. The rise of greater accountability in today's K-12 assessment model empowers instructional leaders to look beyond their scope to see endless possibilities for both teachers and students. To identify the possibilities for teachers and students, an instructional leader must take a deeper look to identify barriers that hinder success. Leaders often find themselves engrossed in the day-to-day work, which distracts their focus and efforts to bring about effective change. Digging deeper into the root cause requires the instructional leader to create a shared purpose for teaching and learning. Precisely, one that fosters a community of trust, respect, and teamwork. As a result, the instructional leader holds significant influence to bring about change for campus and student success. The road is not always easy but if the instructional leaders decide to look deeper, the journey to success is clear. It is through this lens that guides the leader to inspire all stakeholders to become a part of the process of change. How this drives teacher and student success, one may ask? The following elements help and shape the plan for success:

a) Effective communication the vision and mission;

b) Allow feedback on the vision and mission;

c) Redefine the vision, mission, and implementation based upon the feedback;

d) Host community forums about the new direction;

e) Solicit feedback from the community forums;

f) Implement the change initiative;

g) Monitor and adjust;

h) Evaluate progress;

Change is only actualized in the mindset of the instructional leader, which activates the will and vision for success. By doing this, the voice of all stakeholders is heard and, in turn, brings a solution focus initiative for academic success. Moreover, buy-in creates a space and opportunity for the vision to take root in many different forms. Those forms are the undercurrent of student success by which teachers and community leaders assign practices that will assist in creating skillful educators and academically engaged students for success. The instructional leader creates the community of practice to bridge the work of collaboration and instructional feedback. This is as an integral part of the instructional culture - a culture that models itself around the continuous improvement model. Specifically, this model centers around outcome-based professional development practices that empowers, enforces, and activates teacher effectiveness based on sound instructional practices, instructional delivery, and assessment. According to Hook (2017), the Teacher Professional Development (TPD) model is a continuous cycle of improvement that is characterized by the following:

a) Exploration - giving teachers an opportunity to explore instructional strategies to drive student success.

b) Reflection - allow teachers an opportunity to reflect on instructional practices and delivery through an effective coaching model. Utilizing a well-development campus walkthrough tool to adequate support the area of challenges and promises.

c) Discussion - allowing time for collaboration and discussion of best practices that work with colleagues to activate a byproduct of a highly engaged culture of instructional feedback and practice.

d) Application - providing an opportunity and space for teachers to apply instructional practices learned. Diving into assessment data that charts student success.

e) Monitor and Adjust - allowing teachers the time to monitor and adjust their instructional delivery to match student weakness while supporting student strengths. 
All of these elements of TPD provide a rich environment for teacher collaboration, instructional feedback, and improved teacher practices. Furthermore, it allows teachers to grow professionally and their students to grow deeper academically (Hooker, 2017).

ISSN: 2574-1241

DOI: $10.26717 / B J S T R .2018 .11 .002085$

Derrick Love. Biomed J Sci \& Tech Res

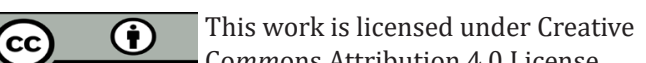

Submission Link: https://biomedres.us/submit-manuscript.php
The quality of the investment in teacher development brings about a greater community of practice. As a result, it bridges the gap between teacher skill deficit and building a teaching and learning community that thrives in the classroom.

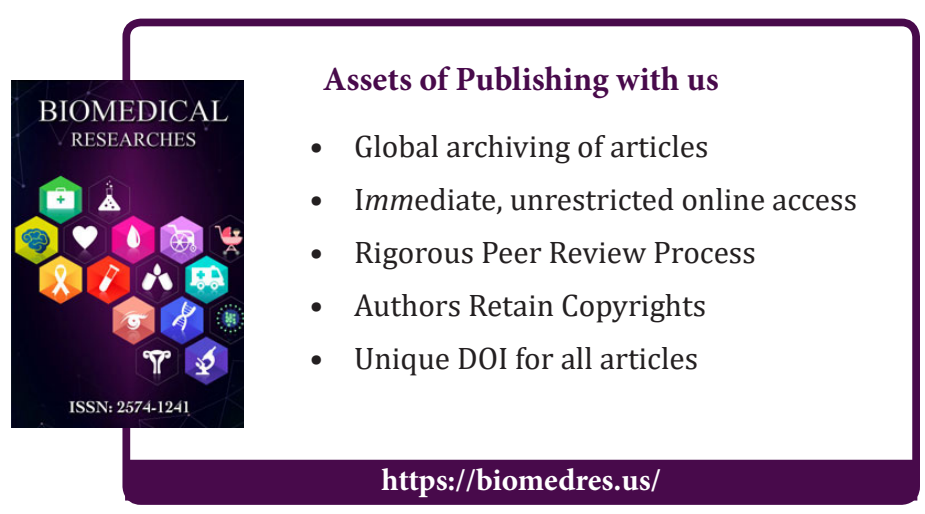

